\title{
The Role of International Standards in Improving the Quality of Enterprises
}

\author{
Kheyri Umudova \\ ${ }^{1} \mathrm{PhD}$. Student, Azerbaijan State Economic University, Faculty of Expertise and Standardization, \\ Standardization and Certification Department \\ E-mail: xeyri.umudova@gmail.com

\section{Leyla Yusifova} \\ ${ }^{2} \mathrm{PhD}$. Student, Azerbaijan State Economic University, Faculty of Business and management, Business \\ management Department \\ E-mail: 1.yusifova@unec.edu.az
}

\author{
Konul Azizova \\ ${ }^{3} \mathrm{PhD}$. Student, Azerbaijan State Economic University, Faculty of Expertise and Standardization, \\ Standardization and Certification Department \\ E-mail: k.ezizova@yandex.com
}

Article History: Received: 10 November 2020; Revised 12 January 2021; Accepted: 27 January 2021; Published online: 5 April 2021

\begin{abstract}
One of the main problems facing organizations that exist today is adapting to the conditions of market economy and to protect the position it has reached in the market. Recently, as the main result of the rapid development of science and technology the world economy put the high quality of produced products and offered services to enterprises as the main requirement. Therefore, entrepreneurs prefer the use of International Standards that have been tested successfully by many enterprises in many developed countries around the world. Compliance with these requirements will give the company the advantages of increasing image, profits, reducing production costs and losses, as well as access to the international market. High quality of the product, its competitiveness and very easy access to foreign markets are achieved by implementing the requirements of International standards such as ISO 9001, GOST P ISO 9001, EQS, GMP, HACCP, QS 9000, OHSAS 18001 etc.
\end{abstract}

Keywords: International Standards, quality, enterprises, products.

\section{İntroduction}

As economic reforms are developing in modern conditions, quality has shown itself as a sphere of focus. Quality has proven to be of great potential in modern times as one of the foundations of the economic and social development of different countries. At present, the main challenge facing enterprises is the creation of a quality system that ensures the production of competitive products and that the system is always in operation. The experience of developed countries shows that improving the quality is a powerful force that affects the economy. In order to ensure dynamic development of the enterprise, increase sales, customer satisfaction and trust, each organization should determine the quality system, which, in its turn, is possible by applying international standards. Because foreign organizations and buyers in the international market prefer the organization that meets the requirements of international standards from the organization that has two analogical products. Thus, the application of international standards in business subjects is the most effective and affordable way for increasing competitiveness of products and services in the world market. Enterprises should build a quality system based on the requirements of international standards; the system should be fully accessible to all workers, including the management, regularly making necessary changes and improvements, and the steps to be taken, as well as the specificity of each firm during the implementation. 
1. What is Quality?

Quality is seen as the basic condition for the existence, growth and development of the enterprises. This understanding is strikingly expressed by such utterances as "today's quality is the assurance of tomorrow" or "promoting quality is securing the future". The concept of quality is a very unclear concept. Quality is often understood as "quality of goods and services" or "product quality". However, there are many factors that bring out product quality and all these elements constitute a dimension of quality in itself. Product quality is essentially the result. The main quality elements that determine this result are:

- leadership quality,

- management quality,

- human quality,

- system quality,

- process quality,

- hardware quality.

The words of the famous Japanese management scientist Masaaki Imai put it very well: "When it comes to quality, product quality is often the first thing that comes to mind. However, this is not true ... There are three building blocks: hardware, software and human ware. Quality starts with people. Hardware and application rules can only be mentioned after the human is placed in the right place. "(Imai, 1997; 41-42.) Another famous Japanese quality expert, Kaoru Ishikawa, defines quality as follows: "In a narrow sense, quality means product quality. In a broad sense it is quality, work quality, service quality, communication quality, process quality, people quality, system quality, firm quality, quality of objectives, etc. (Ishikawa, 1995; 47.)

Another quality expert, Joseph M. Juran, defines quality as suitability for use, while Philip B. Crosby defines "quality is conformity to desired properties". (Hunter, 1993). Quality In ISO 9000. All of the features that are based on the ability of a product or service to meet specified needs. Based on the various quality definitions given above, we can say that quality is a philosophy of life and understanding of life. Because quality contributes to increase customer satisfaction, competitiveness and profit of enterprises, employee satisfaction, decrease in costs and expansion of market shares of enterprises. Quality begins with the plan-do-check-act (PDCA) cycle and the standard of compliance (scheme 1).

\section{2. İnternational Standards}

Over time, scientific innovations are rapidly replacing each other, and consumers' demand for products and services is growing. Payment of such requests requires certain costs and funds. The "high quality" demand of the consumer leads to high costs and costs. For this reason, most manufacturers use low-quality materials, raw materials, or do not follow the rules applicable in the production process to reduce costs. This may lead to a decrease in the quality of the product produced, damage to the health of the employees, consumers and the environment involved in the production process and bankruptcy of the producer. Therefore, there was a need for the development of a system that provides both quality security to both workers and consumers, providing high quality with less cost and less funding. It would be appropriate to apply standardized technical documents, which are standard projects developed by reputable international organizations and periodically renewed by major manufacturers and organizations. International standards are very different depending on the field of application, and in the developed countries of the world, giants have made a lot of money thanks to the implementation of these standards. Normative documents, including guidelines for the implementation of these standards, have been developed by the relevant International Organizations. Although some countries have implemented these standards, many have adapted and harmonized the standardized project with national standards. 


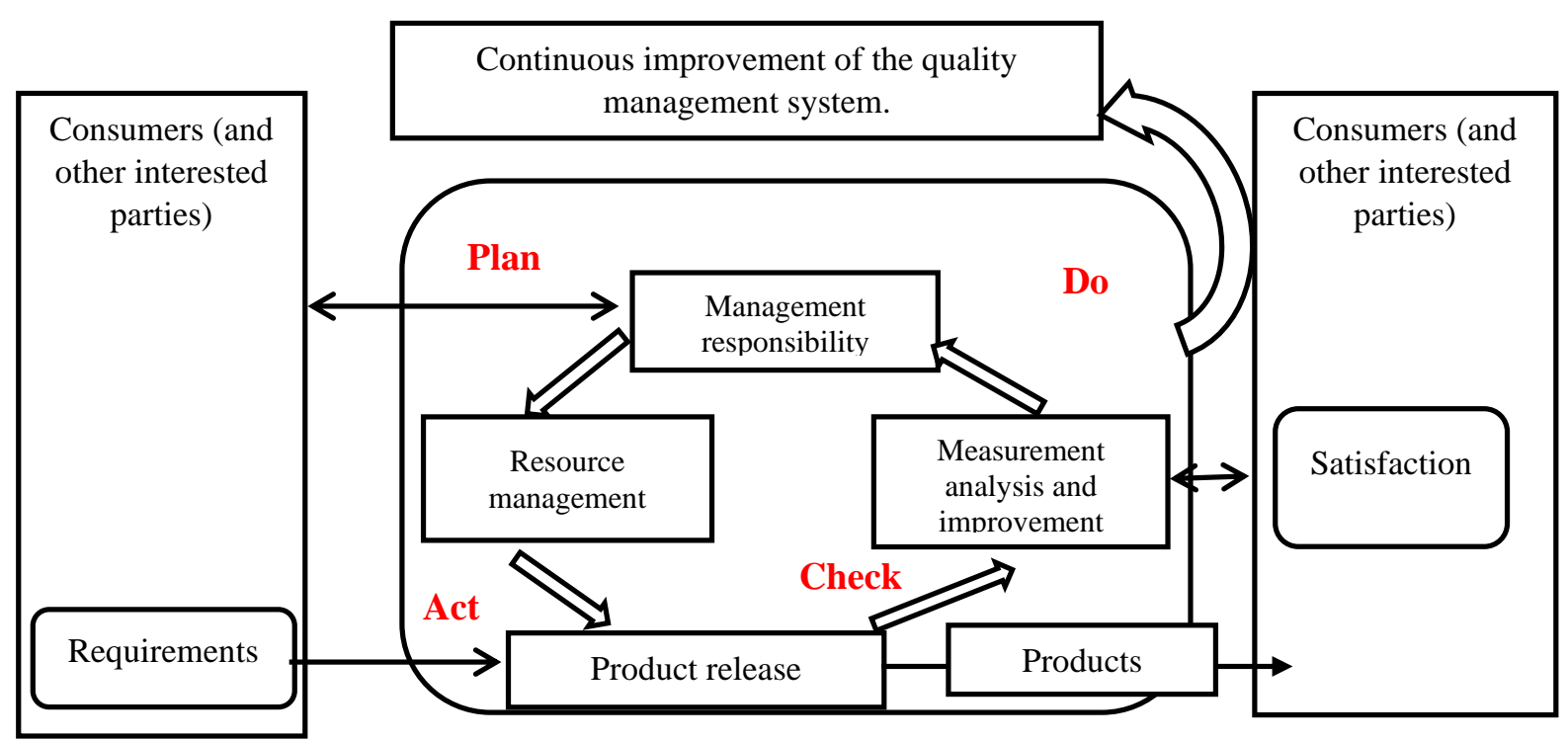

Figure 1. Basic provisions for the introduction of a quality management system, ISO quality management guidelines, reference books.

Professor C. Storz found that many companies have implemented ISO 9000 Quality Management as partial or empty "barking" as a result of research in Japan and some other countries. That is, the reputation of the standard is used to gain customer confidence, but its requirements are not met, there is no relevant record and everything remains in its original form. However, if the standard applies to eligible production process participants, resources, procurement, transport and storage, significant improvements and large amounts of revenue can be generated along with the various stages. This can be seen from the research of many researchers based on world practice. Since the establishment of the first quality standards in the world practice, these standards have been tested by companies operating in many different fields and the results obtained have been continuously improved. These standards include ISO 9001, GOST P ISO 9001, EQS, GMP, HACCP, QS 9000, OHSAS 18001 and others. can be an example.

\subsection{ISO International Standards}

Currently, the most common international standard for quality improvement and low costs in most countries around the world is the ISO 9000 series of standards. The ISO 9000 standard family is including ISO 9000, ISO 9001, ISO 9004 and ISO 19011 standards, and is used for quality management and quality system setup. There are hundreds of accredited bodies in the world that carry out certification on this standard. 


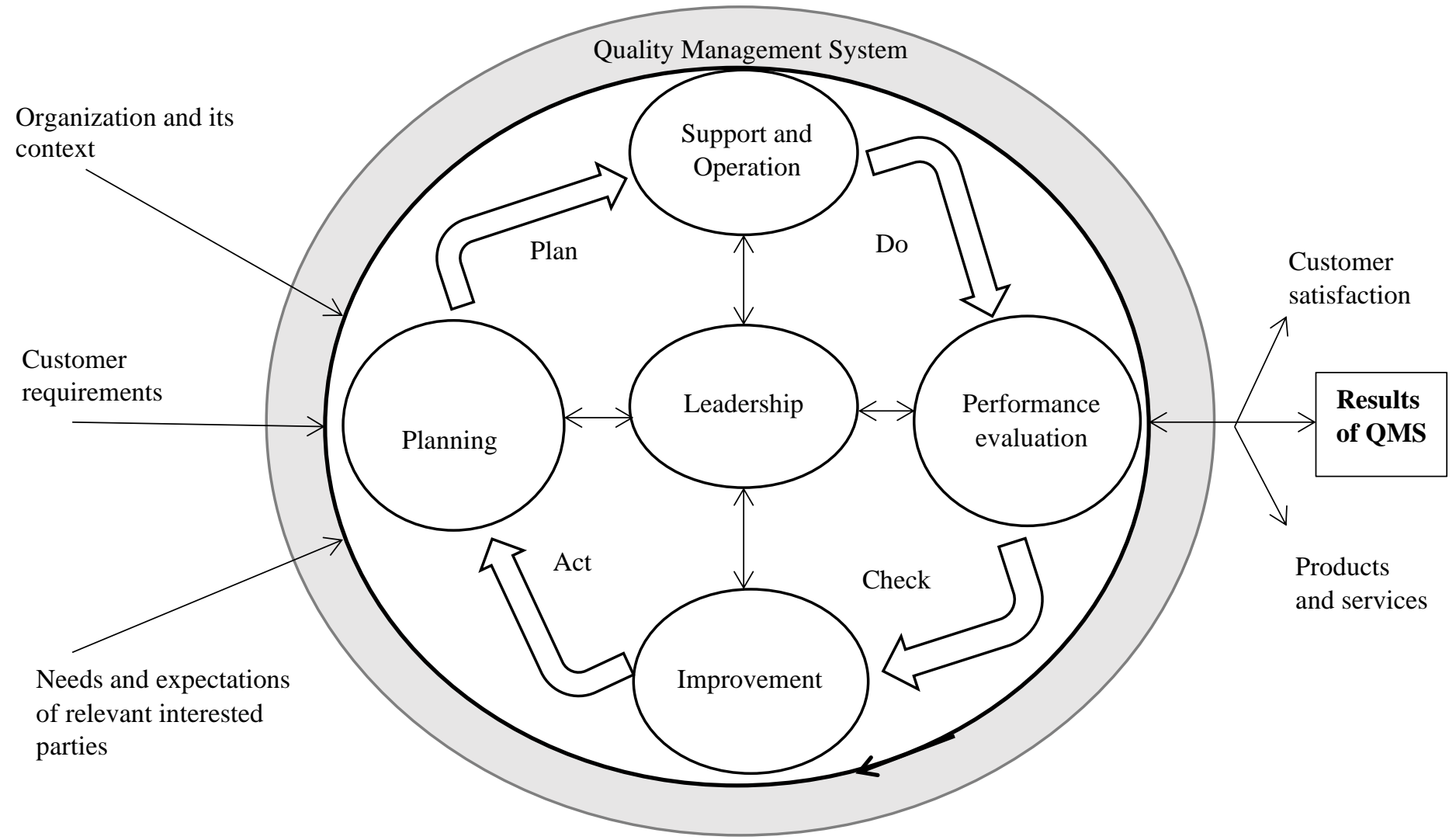

Figure 2. Implementing QMS according to ISO 9000

The application of this standard in enterprises and organizations, as well as certification of this standard, is entirely voluntary. The standard is applied gradually to all stages of production. The standard also encompasses employees' training by increasing their qualifications and competences and motivating them in different ways.

The process-based quality management system model is shown in figure 2 . This illustration shows that there are some inputs in this process like customers' requirements, needs and expectations of interested parties. The output of the process is the result of the QMS that incorporates the organization's products and services, which should lead to customer satisfaction. The model shown here covers all the requirements of this International Standard [14].

The standard is reviewed every five years considering the disadvantages and making appropriate adjustments. The following five major objectives were identified in the 2000 revision of the Standard:

1. Meet the needs of producers, consumers and stakeholders.

2. Being beneficial to every size organization.

3. Availability in all areas.

4. Simple and easy to understand.

5. Coordination and integration of the quality management system with business processes.

Later, the standard was revised in 2008 and 2015. Finally, quality management principles have been added to the standard. These include customer focus, leadership management, employee engagement, process approach, approach to management system, sustainable development, decision-making on facts, and mutually beneficial relationships with suppliers.

Here are some results of implementing İSO 9001 standard by different stakeholders, Bosch Communications applied this standards requirements : in just 11 months and earned certification to ISO 9001, also to AS9100 which is the international QMS standard for the aerospace industry. the U.S. Department of Agriculture's Process Verified Program used the ISO 9001 standard in order to estimate the quality management systems of 
enterprises which are operating in the agricultural sector. In the procurement process, suppliers are required to meet the requirements of ISO 9001 as suppliers' criteria and to require quality assurance managers to become ASQ Certified Quality Auditors. This, in turn, helps save millions of dollars in air force, and the supplier can predict critical defects in products and services.

Since the application of this standard is based on auditing and evaluation of audit results, appropriate procedures are being prepared to carry out the audit based on the requirements of ISO 19011. There are 6 phases for the audit, which include initiating the audit, preparing the audit, conducting the audit, the preparation and dissemination of the audit report, the completion of the audit and its execution. (SFS-EN ISO 19011, 2011.)

\subsection{Environmental Quality Standards (EQS)}

In 2008, the European Parliament and Council first issued the Environmental Quality Standards Directive. In order to achieve good surface water chemical status and in accordance with the provisions and purposes of Article 4 of this Directive, this publication provides priority substances and environmental quality standards (EQS) for certain pollutants as foreseen in Article 16 of the Water Framework Directive 2000/60 / EC (WFD) reveals. As a European directive, each Member State has a plan to assess water objects and comply with annual average and maximum concentrations, as shown in the document. (https://www.aweimagazine.com/article/environmental-quality-standards-1177)

The original EQS (2008) supporting documentation 3 does give some guidance on standard analytical methods that may be employed for the analysis of pollutants; however, even at this time it was acknowledged that standard methods may not meet the required levels and since 2013 most of the EQS levels have been revised to lower values. EQS levels are largely derived from ecological and human toxicology data 4 and as such are not necessarily representative of what existing laboratory techniques are able to deliver, hence the setting of an EQS is a key driver in the innovation cycle for new and improved techniques.

Achievement of EQS should bring a considerable number of benefits, but it is difficult to quantify these on the basis of the information available. The reduction of water pollution levels will bring several direct economic benefits. First and foremost, reducing pollution levels will reduce treatment costs for some major water uses, in particular drinking water and process water for industry. Second, the proposed measures will lead to cleaner sediment, which means reduced inputs of harmful substances and hence cheaper management of waste during dredging operations because of the lower contamination. Third, the requirement to reduce losses of substances into the environment will trigger the development and commercialization of cleaning - and cleaner technologies.

Fourth, cleaner water will improve the quality of the fish and shellfish which are sold by the fishing or fishfarming industries. Cleaner waters will improve productivity and reduce the accumulation of dangerous substances in fish tissue, thereby reducing human exposure to hazardous substances.

\subsection{Good Manufacturing Practice (GMP)}

GMP is not informed of how the products are produced. There are some common principles that need to be checked during production. There are many ways to follow GMP principles when planning an enterprise quality system and production process. The choice of the most effective and productive path is in the hands of the enterprise. The formalization of GMP commenced in the 1960s and they are now in effect in over 100 countries ranging from Afghanistan to Zimbabwe.

The GMP is based on Good Manufacturing Practice Guidelines published by the US Food and Drug Administration, the Federal Food, Drug and Cosmetic Act. This regulation requires proactive steps to ensure that manufacturers and medicines, medical devices and certain food and blood packaging products are safe, clean and effective. GMP rules require a qualitative approach to production and allow companies to minimize or eliminate contamination, mixing and faulty samples. This protects consumers from buying an ineffective or even dangerous product. Failure to comply with GMP rules will result in punisments.

Worldwide, there are now around 30 different official national and super national statements on GMP. These have been published variously as guides, codes and regulations and of the 30 or so of them, two stand out as being the most influential and most frequently referenced: The United States Current Good Manufacturing 
Practice (cGMP) Regulations and the European Commission's "Good Manufacturing Practices for Medicinal Products for Human and Veterinary Use”. Third, WHO (World Health Organization) version of GMP is used in pharmaceutical regulators and pharmaceutical industries in more than 100 countries worldwide. Nally, 2007).

All GMP rules are based on several principles:

- They should minimize the quality risks during the production and distribution of drugs.

- Hygiene rules must be observed in production areas, laboratories and warehouses.

- Working conditions and operating principles should be checked to prevent contamination of pharmaceutical products.

- Production processes must be clearly defined, approved and monitored to ensure compliance with the Guidelines.

- Instructions should be clearly and clearly stated.

- Throughout the life of the product, the process should be monitored and improvements should be maintained if necessary.

- The system must be available to recall any batch of goods.

- Complaints about the products sold should be investigated, the causes of quality defects should be clarified and preventive measures should be taken against defective products.

\subsection{Hazard Analysis and Critical Control Point (HACCP)}

The foundations of the HACCP system were laid at Pillsbury, a company that produces food for NASA (American National Aerospace Association). NASA asked the company to produce $100 \%$ safe foods for space programs. As the existing security systems were insufficient, a new method had to be developed and Pillsbury Company has worked together with NASA, Natic Laboratories of the American Armed Forces and the American Air Force Space Laboratory project team (Bauman, 1995: 1). Although the first step for the HACCP system was taken in 1959, it was officially announced to the public in 1971 at the National Food Preservation Conference. After this opening, the first HACCP document was published for FDA (Food and Drug Administration) in 1973 and the company trained FDA inspectors (Bauman, 1994: 67). In 1991, the Codex Alimentarius Committee on Food Hygiene, consisting of international FAO-WHO joint experts, launched an initiative to prepare a guideline for the international applicability of the HACCP system and was published in 1993 (Bauman, 1995: 2). HACCP is a management system that aims to control the safety hazards that may arise in food and is accepted as the best approach by many institutions and scientists (Khandke and Mayes, 1998: 103). By identifying, assessing and controlling the hazards that may arise, it is aimed to prevent hazards before they exist. Unlike other systems, it does not rely on control of the final product. It is a proactive approach that intervenes in the whole process (FDA, 2004: 1). The basic principle for the success of food safety management is to establish a system in which HACCP, prerequisite programs and safe process design are carried out together and verify the applicability.

\subsection{Occupational Health and Safety Assessment Series (OHSAS 18001)}

In the modern world, expectations from customers and consumers have increased dramatically. The term "quality" questions the extent to which businesses comply with occupational health and safety requirements, and whether they have a safe and healthy working environment for the interested parties and their ongoing development. The BS 8800 Occupational Health and Safety Management Guide, was published in 1996 by the British Standards Institute (BSI) and it was the first standard instruction on health and safety. At the same time, standards were published in other documentary institutions. However, these standards differed in content and practice. Subsequently, a commission was established in the United Kingdom to establish an internationally recognized health and safety standard by BSI, and as a result of the Commission's work, the OHSAS 18001 standard, shortened by combining the first letters of the Occupational Health and Safety Assessment Series, was created in 1999. OHSAS 18001 is a risk analysis management system developed for heavy and hazardous workplaces worldwide.

OHSAS 18001 specifies the conditions of workplaces that want to minimize work-related accidents and occupational diseases and meet legal requirements for occupational health and safety. This management system aims to take necessary precautionary measures by prioritizing and minimizing potential hazards. 
1. Protecting employees: Protect employees from the harmful effects of the workplace and ensure that they work in a comfortable and safe environment.

2. Ensure production safety: Minimize labor and workday losses due to work accidents and occupational diseases, thus improving work efficiency

3. Ensure the safety of the enterprise: fire, explosion, equipment damage prevention in the building, measures taken in the activity area.

\section{Method}

This article provides a literature review to describe international standards, their role and benefits in companies. Thus, a computer search was made. Studies on international standards were investigated. These studies have been reviewed to determine the most common profits and advantages of applying international standards based on literature.

\section{Finding}

The standards ensure that the quality of the products and the safety requirements are met as they are prepared using the latest technologies (CEN-CENELEC-ETSI, 2010). In this way, the companies have a competitive advantage in the market as they can offer better quality and safer products and services. The implementation of ISO 9001 Quality Management Systems puts companies in a superior position in the market.

Lee divides the gain from the implementation of the standards into three parts: benefits from internal operations, benefits from customer relations, benefit from relations with subcontractors.

Examples of benefits from internal operations include increased team spirit, reduced worker conflicts, prevention of waste and others. Benefits from Customer Relations include increased sales as a result of new customers arriving, receiving fewer complaints from existing customers, and extending contract terms with customers. The benefits obtained from relations with subcontractors can be demonstrated by certification of subcontractors, establishing better relationships with subcontractors, and improving control of subcontractors (Lee, T.Y. (1998).

Nield and Kozak saw the benefits of implementing international standards in improved communication systems, increased customer satisfaction, increased competitive advantage, nationwide recognition, and positive changes in human resources (Nield, K., \& Kozak, M. (1999)) Casadesus and Karapetrovic said these benefits result in financial results, operational results and customer-related results(Casadesús, M., \& Karapetrovic, S. (2005)) By applying international standards, many businesses use the benefits it brings. For example, the application of ISO 9001 improves documentation and operating instructions.

Examples of other benefits that businesses can receive include improving their image and improving the quality of their products and services, as well as having a certificate that enhances their image in the eyes of their customers. At the same time, greater control over internal processes can improve the quality of the product or service.

The EQS application provides the community with the following benefits:

- Maintain high-quality areas that grow rare plants and live animals

- Protecting water basins and wetlands to prevent soil erosion, floods

- Provide them with clean water to meet the needs of society

- Encourage society to be environmentally conscious

- Improve air quality

- To prepare effective and cost effective waste recycling programs the OHSAS 18001 application provides the business with the following benefits:

- Prevents most cases of workplace death, illness, injury, property loss and other losses

- Provides protection of resources by integrating occupational health and safety activities with other activities.

- The value given to occupational health and safety activities reflects the management's attitude.

- Ensures the credibility of the enterprise in society by increasing the credibility of the enterprise.

- Increases employee motivation and participation, increases trust and loyalty to the business.

- Occupational diseases and accidents are reduced and labor loss is prevented. 
- Provides better health and safety risks both today and in the future.

- Customer satisfaction and loyalty are beneficial.

- Reduces penalties and compensation by preventing and slowing down production due to accidents and diseases, minimizing financial costs.

GMPs are a set of industry best practices to help ensure the safety, quality and efficacy of a natural health product. The implementation of GMPs will help reassure consumers that the same level of care and testing is found throughout the industry.

There are many benefits for companies who implement a fully-compliant GMP program, which will substantially increase the quality of their product, and increase revenues and customer satisfaction. Some of the benefits from a proactive approach to a compliant GMP program include:

1. Operating costs drop as rework and penalties due to non-compliance reduce and efficiencies increase.

2. Help customers, employees, stockholders, regulators and competitors develop sustainable respect for an organization which demonstrates commitment to NHP safety

3. Preparation for HACCP certification

4. They can use online newsletters and other internet forums to educate their customer

With the introduction of HACCP-based processes, the following advantages are achieved:

- Protects investments

- Prevents damage to customer health

- Food safety standards rise

- Complies with the Manufacturing Act

- Food quality standards are rising

- Simplify the process of producing safe food

- Increases teamwork and labor productivity among employees.

The most commonly used standards in Baltika Breweries, established in 1990, can be found in ISO 9001: 2008, ISO 14001: 2004, OHSAS 18001: 2007, HACCP, FSSC 22000, ISO 22000, ISO 10002: 2004, European Brewery Convention standards (for malt and beer), Many GOST standards (for malt and beer, storage, aftersales service), Federal regulations for the transport of food and beverages. The economic benefits of the $\begin{array}{llllll}\text { standards } & \text { were } & \text { US } & \$ & 94.1 & \text { million. }\end{array}$ Established in the Senegalese capital Dakar in December 1995, the Senegal des Eaux (SDE) played a key role in establishing a reliable urban drinking water system for the country. In the enterprise widely used in ISO 9001:2008, ISO 14001:2004,OHSAS 18001:2007, Some French national standards on water quality and testing, Some Senegalese national standards on water discharge and air pollution. The economic benefits of the standards were US \$ 2.77 million.

Holcim Lebanon S.A.L. (HL), was founded in 1929 by Swiss Holcim Ltd., one of the largest cement producers in Lebanon. as a subsidiary of the company. Over the years, it has created an enterprise image that offers ecologically clean and high quality products among its customers. Holcim Lebanon is currently the leading cement producer. İn the enterprise widely used in ISO 9001:2008, ISO 14001:2004, NL 53:1999, Cements Portland cement types (Lebanese national standard), European standards (EN) on cement composition and testing, Some ASTM standards on cement. In 2001-2011, the entity gained a profit of US \$ 1.1 million from the application of standards. https://www.iso.org/files/live/sites/isoorg/files/archive/pdf/en/ebs_case_studies_factsheets.pdf

\section{Results, Conclusions and Recommendations}

Businesses achieve the following advantages by applying international standards:

1. By demanding a quality management system that reflects modern needs from its suppliers, it can consistently provide high quality raw materials, this makes it possible to reduce the number of laboratory tests and to transfer some laboratory personnel to other operations.

2. The Management System, based on ISO 9001 and ISO 14001, has a positive effect on labor productivity labor productivity by facilitating processes, uniting acquisitions and optimizing collaboration between factories. 
3. The company achieves strict control over the production processes thanks to the ISO 9001 quality management system and helps it gain a reputation as a high quality manufacturer.

4. Standards and certification marks are clearly identified in the company's product catalogs and emphasize the importance the company attaches to standards as a means of gaining international reputation and entering foreign markets.

5. International food and hygiene standards provide a solid framework, simple objectives and clear criteria. It also supports documentation, information exchange and information transfer and provides a basis for meeting the essential elements, performance indicators, key elements, and quality and safety requirements that are essential to conducting the company's fully automated processes.

6. Standards simplify the design selection process and at the same time lead to regular manufacturing and installation of equipment and components that help improve design quality and work efficiency.

7. Good product quality reduces waste, increases customer confidence and enables the company to sell higher value goods, thereby increasing revenue.

8. Standards helped establish a culture of continuous development in the company.

9. Standard development and early adoption of the standards provide the company leadership in its field. 10. Applying standards continuously improves environmental performance and cost reduction due to product quality and material savings.

11. Standards help create a culture of quality consciousness at all levels of the company.

12. Standards help manage business operations more reliably and efficiently.

13. Standards help to create a comprehensive distribution network as well as productive, quality production and product branding.

14. Improving environmental and safety management strengthens the company's reputation, while productive service enhances customer satisfaction

\section{References}

1. Bauman, Howard E. (1994). The Origin Of The HACCP System And Subsequent Evolution. Food \& Science Technology Today. Volume 8: 66-72. Bauman, Howard E. (1995). The Origin And Concept Of HACCP. Advances in Meat Research. Volume: 10, 1-7.

2. Bauman, Howard E. (1995). The Origin And Concept Of HACCP. Advances in Meat Research. Volume: 10, 1-7.

3. Casadesús, M., \& Karapetrovic, S. (2005). The erosion of ISO 9000 benefits: a temporal study. International Journal of Quality \& Reliability Management, 22(2), 120-36.

4 CEN-CENELEC-ETSI, (2010), Standards Supports Innovation and Growth, Avrupa Standart Kuruluşları Kitapçığı, Brüksel.

5. FDA. (Food and Drug Administration) (2004). U. S. Department Of Health and Human Services Public Health Service Food and Drug Administration 2001 Food Code (Updated April 2004) http://vm.cfsan.fda.gov/ acrobat/fcannex5.pdf. (28.10.2007).

6. HUNT, V. Daniel, Quality Management for Government: A Guide to Federal, State and Local Implementation, Milwaukes, Wis.: ASQC Quality Press, 1993.

7. https://www.aweimagazine.com/article/environmental-quality-standards-1177

8. https://www.iso.org/files/live/sites/isoorg/files/archive/pdf/en/ebs_case_studies_factsheets.pdf

9. http://isoconsultantpune.com/apb-consultant-process-approach/ Pretesh Biswas

10. IMAİ, Masaaki ,. Kaizen -Japonya'nın Rekabetteki Başarısının Anahtarı- İstanbul: BRİSA Yayını, 1997. 11. ISHIKAWA, Kaoru, Toplam Kalite Kontrol, İstanbul: KalDer Yayınları, 1995.

12. Lee, T.Y. (1998). The development of ISO 9000 certification and the future of quality management: a survey of certification firms in Hong Kong. International Journal of Quality \& Reliability Management, $15(2), 162-77$

13. Nally, J. D. (Ed.) (2007). Good Manufacturing Practices for Pharmaceuticals, Sixth Edition, Informa Healthcare USA, Inc., ISBN 10: 0-8593-3972-3 \& ISBN 13: 978-0-8493-3972- 1, New York

14. Nield, K., \& Kozak, M. (1999). Quality certification in the hospitality industry: analyzing the benefits of ISO 9000. The Cornell Hotel and Restaurant Administration Quarterly 